\title{
Defining Challenges and Opportunities of Intermarriages and Sexual Relations for African Migrants and South Africans in the City of Cape Town, Western Cape
}

\author{
Marius D. Mbetga
}

\begin{abstract}
This article focuses on the challenges and opportunities regarding marriages and sexual relations between South Africans and African migrants living in the City of Cape Town. In this specific context, the study examines the experiences of African migrants and South Africans of all races and backgrounds. The focus of this study is to explore the challenges and opportunities of marriages and sexual relations between African migrants and South Africans in general. For the theoretical framework, this study relies on contact theory and on intergroup theory. The data analysed is based on interviews from African migrants and South Africans living in the City of Cape Town. The complexity of this phenomenon reflects xenophobia, intolerance and racism as cultural legacy on the one hand, and on the other, multiculturalism and diversity as a new conceptualisation of a globalized world. Both co-exist within the same society. This study found that, while there are challenges to marriages and sexual relations between African migrants and South Africans, there are also opportunities generated for and by these intermarriages and relationships. By focusing on the challenges and opportunities, this study offers insight into the marriages and sexual relations between South Africans and non-South Africans in present-day post-apartheid South Africa.
\end{abstract}

Keywords: Intermarriages, sexual relations, social contact, xenophobia, racism, multiculturalism. 


\section{Introduction}

Migration into South Africa provides challenges and opportunities for marriages and sexual relations between South Africans and African migrants in the country, and more specifically in the City of Cape Town. Both South Africans and African migrants living in contemporary post-apartheid South Africa are deeply or lightly, directly or indirectly concerned, and sometimes disturbed, about marriages and sexual relations between local South African citizens and migrants from other African countries of diverse backgrounds.

In the past, and more precisely during the apartheid era in South Africa (1948-1994), official segregation laws, religious, cultural, racial and racialist emphasis in the country have been placed on discouraging interracial sexual relations and mixed marriages. After the end of the apartheid regime in 1994, conservative cultures and their legacies have softened their position by progressively, but not totally, welcoming mixed marriages and sexual relations. Many marriages and sexual relationships in present-day postapartheid South Africa have been improved by the energy and interest of nonSouth Africans and their South African partners or spouses.

It appears that South Africa is the main destination in the African continent for African migrants who did not have the choice or the opportunity for mainstream destinations, such as the United States of America, Europe, and Australia. In this respect, African migrants play a relatively important role in intermarriages in South African society through marital blending and marital assimilation.

The focus of this study is on marriage and sexual relations between South Africans and non-South Africans from other African countries. Participants for this research are South Africans and African migrants living in the City of Cape Town who are intermarried or not, or who do or do not contemplate or consider marriage and or sexual relations outside their respective homelands and backgrounds. These backgrounds may be based on nationality, race, culture, religion, social class and or social status. The social context and background to the study are discussed below.

\section{Social Context and Background to the Study}

Human mobility, and social migration in particular, appears to be a new conceptualization into understanding a diversified and multicultural society. Migration is becoming a process and practice of integrating or mixing peoples 
inter-nationally, inter-racially, inter-culturally, and inter-religiously into a larger sociological sphere. There are many reasons for this as George Fredrickson (2002: 4) points out 'The defeat of Nazi Germany, the desegregation of the American South in the 1960s, and the establishment of majority rule in South Africa suggest that regimes based on biological racism or its cultural essentialist equivalent are a thing of the past. But racism does not require the full and explicit support of the state and the law. Nor does it require an ideology centered on the concept of biological inequality. Discrimination by institutions and individuals against those perceived as racially different can long persist and even flourish under the illusion of non-racism'.

In relation to this phenomenon, it is significantly expected to understand the South African context with reference to marriage and sexual relations in apartheid and post-apartheid South Africa. In the past, and more precisely during the apartheid era in South Africa, official segregation laws, religious, cultural, racial and racialist emphasis in the country have been placed on discouraging interracial sexual relations and mixed marriages between 'citizens' and 'natives' of the same country. Some writers are of the view that the roots of racism in South Africa existed before apartheid. 'Long before apartheid was enshrined within the pages of the great statute books of the Republic of South Africa, it already existed as part of the unwritten laws of this country, as well as other countries in Africa under British colonial rule' (Credo Mutwa 1986: 13).

During the apartheid period (1948-1994), South Africa was isolated by many African countries. For this reason, few African migrants entered the country. 'The South African government also tried to accommodate itself to the age of decolonization. It offered dubious independence to the overcrowded 'homelands', from which African migrants went forth to work for limited periods in the mines and factories of the nine-tenths of the country reserved for a White minority that constituted less than a sixth of the total population' (Fredrickson 2002: 4).

The fall of the apartheid regime in 1994 opened the doors, through diplomatic ties, for many Africans to migrate and hunt for better life opportunities in South Africa. Many of these African migrants appear to be young males, married or unmarried. Some have left behind wives, children and / or fiancées, in their native countries. Their migration into South Africa suggests some challenges and offers some opportunities for intermarriages, marriage relationships and sexual relations. This stimulates a space for a research problem (Mwakikagile 2008). 


\section{Research Problem}

Globally, many studies have been conducted on marriages and sexual relationships between migrants and people of different racial and diverse cultural backgrounds. Some studies are of more important significance. In the Asian context, Masaaki Satake (2004) focused on the configurations and tendencies of intermarriages between Filipino women and Japanese men from the 1980s to 2004, and Matthijs Kalmijn (2010) on the social consequences of intermarriage in the relation of children born of a mixed marriage. In the American context, Sheryline Zebroski (1999) focused on the social order and mixed marriages; Pratikshya Bohra-Mishra and Douglas Massey (2015) and Miao Chi (2015), on marital assimilation; Dorit Roer-Strier and Dina Ben Ezra (2006) and Cukras-Stelągowska (2016(, on cultural adaptation of mixed marriage. In the European context, Davide Azzolini and Raffaele Guetto (2015) focused on the integration and assimilation of immigrants through intermarriages.

Locally in the African context, and especially in South Africa, the existing literature suggests the works of Emily Mapula Mojapelo-Batka (2008) and Did'ho Jean-Marie Kuzituka (2009) focusing respectively on the psychological and materialistic aspects of mixed marriages. However, to the best of my knowledge, it is important to explore the challenges and opportunities of marriages and sexual relations between African migrants and South Africans of all races (White, Coloured, Indian, and Black) in the context of the City of Cape Town. It is in this context that this study contributes to improving the understanding of the area of concern and the body of knowledge in theory and within the practice in this respect. This involves the research question.

\section{Research Question}

The central research question of this study is framed as follows: What are the challenges and opportunities defining marriages and /or sexual relations between African migrants and South Africans in the City of Cape Town? The focus of this research is two-fold; on the one hand, the challenges of intermarriages and /or sexual relations, and on the other hand, the opportunities of intermarriages and/ or sexual relations concerning African migrants from other African countries and South Africans of all races and backgrounds living in the City of Cape Town. 
The main research question suggests the subsequent questions: What are the challenges defining marriages and/ or sexual relations between African migrants and South Africans in the City of Cape Town? In other words, why some African migrants and some South Africans living in the City of Cape Town do not consider marriage and /or sexual relations with people from differing backgrounds? What are the opportunities defining marriages and/ or sexual relations between African migrants and South Africans in the City of Cape Town? Why do some African migrants and some South Africans living in the city of Cape Town contemplate or consider marriage and/ or sexual relations with people from differing backgrounds?

This study takes the perceptions and experiences of African migrants and South Africans of different backgrounds who live in different areas of the City of Cape Town into consideration. The setting in the City of Cape Town, where the study is conducted, is the Cape Town Central Business District. The Central Business District, in the context of this study, is a hub or a junction for many African migrants and South Africans from diverse backgrounds living in the City of Cape Metropolitan Municipality.

This study is significant as existing literature highlights the gaps on marital and sexual relations between locals and migrants (Kuzituka 2009) and on interracial South African couples (Mojapelo-Batka 2008). No study has been done, however, on the marriage between African migrants and South Africans of all races (White, Coloured, Indian, and Black) in the context of the City of Cape Town. The evidence of this study helps to understand the general account of the defining challenges and opportunities of marriages and or sexual relations between African migrants and South Africans from different and or differing backgrounds living in the City of Cape Town. An overview of intermarriage and sexual relations follows below.

\section{An Overview of Intermarriage and Sexual Relations}

There are different types and forms of marriages across the world that can be defined historically, geographically, culturally, racially, economically, legally, anthropologically, and /or sociologically. Society constructs human beings in different races, classes, religions and other socially constructed categorisations and classifications. In this respect, intermarriage can be used as the umbrella concept of interracial, international, intercultural and intertribal marriage. 
In the Asian context, Masaaki Satake (2004) focused on the configurations and tendencies of intermarriages between Filipino women and Japanese men from the 1980s to 2004. For Masaaki Satake, there are factors that increase mixed marriages between Japanese men and Filipino women. The study suggests that these mixed marriages reveal possibilities for different gender and multicultural relations. In this context, there are more opportunities than challenges of intermarriages and sexual relations. Children, who are born of intermarriages, can be sometimes socially or psychologically, positively or negatively influenced by this type of marriage. It is in this regard that Matthijs Kalmijn (2010) focusing on the social consequences of intermarriage in the relation of children born of mixed marriage states that 'Intermarriage has long been considered a core indicator of the integration of ethnic and racial minorities in society'.

The most important reason for this is that when members of ethnic and racial groups marry other groups, this is a sign that these groups accept each other as equals. Intermarriage is also considered important, however, for its potential consequences. 'Intermarriage may reduce group identities and prejudice in future generations because the children of mixed marriages are less likely to identify themselves with a single group' (Kalmijn 2010). In this regard, intermarriage is seen as an indicator and component of mutual acceptance and social integration. Additionally, children of intermarriages are supposed to interact across a group or racial boundaries. This may not necessarily be the case in other contexts.

In the American context, Sheryline Zebroski (1999) focused on social order and mixed marriages. 'Those in interracial marriages keenly perceive the attitudes of the community around them; these perceptions tell us something about the social support that these unions receive. Traditionally, sociologists have studied intermarriage as an indicator of the nature of relationships between diverse people. The theoretical assumption has been that intermarriages are an index of assimilation' (Zebroski 1999: 123). In this regard, the social order and the power relationship play a very big role in mixed marriages. In this context, assimilation as opposed to integration in the previous context is a confirmation of unbalanced relationships among intermarried people. In this respect, a partner is seen as dominant and the other as submissive because of the social order. In relation to marital assimilation, Pratikshya Bohra-Mishra and Douglas Massey (2015) and Miao Chi (2015) point out the importance and the impact of migration. In the context of their 
studies, European and Asian immigrants in the United States are seen as the assimilated.

Dorit Roer-Strier and Dina Ben Ezra (2006) and Cukras-Stelągowska (2006) point out the cultural adaptation of mixed marriages. Their studies reveal that mixed marriage stimulates a multidirectional and multicultural adaptation process. 'Patriarchy and East-West power relations affect mainly the women, having to face marginalization on the basis of their gender and their foreignness. The men undergo a double process of cultural adaptation: to the Western culture and to their native culture after their return' (Roer-Strier \& Ben Ezra 2006: 41). These circumstances point out the challenges of intermarriages.

In the European context, the study conducted by Davide Azzolini and Raffaele Guetto (2015) revealed the integration and assimilation of immigrants through intermarriages. This study suggests the blending of integration and assimilation. In this regard, Davide Azzolini and Raffaele Guetto (2015: 1) state that 'According to the assimilation theory, immigrants' acquisition of the citizenship of the destination country should increase the number of intermarriages as a result of immigrants' enhanced integration. Status exchange theory, instead, would predict a negative impact of citizenship acquisition, as the latter eliminates one of the possible 'rewards' that immigrants obtain in marrying a member of the native population'. It is important to mention the importance of migration in relation to intermarriages. This method of marriage leads to integration or assimilation depending on the social, political and economic circumstances.

With reference to a study on intermarriage conducted in the United States of America, Egon Mayer (1985: 66-67), citing Berger and Kellner, defines: 'marriage in our modern society is a dramatic act in which two strangers come together and redefine themselves [more or less on their own terms without any interference from others]. The drama of the act is internally anticipated and socially legitimated long before it takes place ... and amplified by means of a pervasive ideology, the dominant themes of which (romantic love, sexual fulfilment, self-discovery and self-realization...the nuclear family as the social site for these processes) can be found distributed in all strata of the society'. This view is agreed to a certain extent. In some other contexts, for example, in other settings in Africa, marriage is more than the union between two persons. Marriage is seen under certain circumstances as a 'coming together' of two families or two communities. In this context, the family or the 
community backgrounds of the partners or spouses play a very significant role.

Emily Mapula Mojapelo-Batka (2008) has conducted a study in Johannesburg on interracial couples (White-Black) within the South African context, 'the results of this study indicate that individuals found their involvement in mixed-race relationships to be positive attitude change and a sense of personal growth. Mixed-race couples and their extended families experienced cognitive dissonance which required them to discard their previously internalised racial stereotypes, using strategies such as cognitive differentiation, re-categorization and de-categorization, allowing shifts toward non-racial socially constructed categories' (Mojapelo-Batka 2008: ii).

It is inevitably arguable that not all members of the extended families of the spouses involved in interracial or mixed-race marriages have the same capacity of experiencing and or accepting cognitive differences. Some members of the families see in this context of marriage a rebellious attitude and behaviours of the spouses who in some cases rejected their families and /or are rejected by their own family members. Revolt, rebellion and rejection sometimes destabilize the harmony in and of the families. In an interracial as well as intra-racial marriage, there is by some means a power relation of the dominant and the submissive. In this regard, Delores Aldridge (1978: 357) points out that 'one reason that Black women marry White men is to improve their social status. Of course, this applies to many homogenous marriages'.

A study conducted in the City of Johannesburg by Did'ho Jean-Marie Kuzituka (2009) revealed that 'marriage between Black South Africans and African immigrants or migrants in Yeoville has become an act of profit and interest. Mutual love, respect and the upbringing of children is not important because, in most of cases, couples do not want having children in these marriages .... Openness and frank dialogue are mostly lacking in these foreign - local marriages. Because each partner enters the marriage with a hidden agenda and once the agenda has been fulfilled, he or she walks out of the marriage without taking legal steps of divorce' (Kuzituka 2009: 107-109).

Did'ho Jean-Marie Kuzituka (2009) shares similar views and highlights the commercialization of marriages. He states that because of unemployment, inequality, and poverty that monitor the lives of ordinary Black South African women who are prey for men and more particularly for African migrants who will marry them not for love, but for a hidden agenda, in other words for-profit and interest.

In this context, marriages and sexual relations become purely strategic 
calculations involving a multiplicity of hidden plans from both sides. Strategic calculations consequently involve strategic partners and vice versa. Therefore, marriage and sexual relations in this regard are based on mutual exchange and exploitation. This can be seen as the re-invention of capitalism in present-day South African society. It might also appear, under certain circumstances, that some South Africans and some African migrants get married for romantic love.

\section{A Brief Overview of Racism in Relation to Marriage}

According to George Fredrickson (2002: 8), 'there is a general history of racism, as well as a history of particular racisms, but knowledge of specific contexts is necessary to an understanding of the varying forms and functions of the generic phenomenon with which we are concerned'. Different forms and functions of racism need to be taken into consideration and to be understood by acknowledging the specific contexts in which they occur. Racism, today as a worldwide phenomenon, and more precisely in Germany, in America and in South Africa suggests a general historical view, and also some differences and particularities.

With reference to Germany and South Africa, George Fredrickson (2002: 8) points out that 'contemporary British sociologists have identified and analysed what they call 'the new cultural racism'. John Solomons and Les Back (2002: 36) argue, for example, that race is now 'coded as culture', that 'the central feature of these processes is that the qualities of social groups are fixed, made natural, confined with pseudo-biologically defined culturalism'. Racism is, therefore 'a scavenger ideology, which gains its power from its ability to pick out and utilize ideas and values from other sets of ideas and beliefs in specific socio-historical contexts'. This view undoubtedly brings into discussion the social and historical relationships between race, racism and marriage and or sexual relations in the South African context by trying to understand the significant challenges and the prospective opportunities for and of such human relations and associations.

One of the key questions still remains. Do previous discriminatory measures such as the Prohibition of Mixed Marriages Act, Act No 55 of 1949 - passed by the Nationalist Government in 1949 to prohibit marriages between the race groups and was subsequently repealed in 1985-. change the mentality and the culture of segregation and racism in post-apartheid South Africa? General opinion of the results of this study helps to a certain extent to answer 
this important question.

According to the Population Registration Act of 1950, South Africans were racially classified in four principal groups, namely White, Coloured, Indian and Black. 'Race is defined as a social concept referring to a group of people who share distinct and similar physical characteristics' (Sahistory.org.za, Accessed on 25 November 2016). With reference to these racial groups, the apartheid government criminalised inter-racial or mixed marriages amongst South Africans of different racial groups inside and outside the country. Intermarriages and inter-racial relationships were only decriminalised or allowed in 1985 through the Amendment Act by the same apartheid government.

This amendment gave South Africans the possibility to interracially express their intimate relationships that may or may not lead to marriages. This amendment act did not eradicate the racial inequality and the White supremacy already prevailing in the country. Discrimination and hegemony undoubtedly played an increasingly harmful role in these human relations of intimate interactions and subsequently by creating the power relation of the dominant and the submissive. This repealing of 1985 unsurprisingly contributes negatively or positively to marriages and sexual relations between South Africans and African migrants in present-day post-apartheid South Africa and specifically in the City of Cape Town.

\section{A Brief Overview of Diversity and Marriage}

Delores Aldridge (1978) deeply examined the empirical and theoretical considerations concerning interracial marriages especially in the American context. With reference to these considerations, Delores Aldridge (1978) specifies by citing Barron (1946: 249), that 'Social scientists have maintained the study of intermarriage may provide a precise, quantitative measurement of crucial and related questions such as the process of assimilation, the degree of internal cohesion in individual racial, religious, and ethnic groups, and the extent of social distance between groups of these types'. To a certain degree, these empirical and theoretical considerations seem to be applicable in the South African context of interracial marriages.

Delores Aldridge (1978: 367-8), citing Staples (1973), indicates that 'the intermingling of young adults of different races at the high school and college levels is widely expected to be reflected over the long run in an 
increased rate of intermarriages.... And the fact that large numbers of interracial couples meet on college campuses away from home reduces the amount of parental and community control over the choice of an individual's dating partners. Young people have revolted against traditional institutions and values which have led them to reject the taboos on dating across racial lines'.

Migration of people from other African countries into South Africa and marriage between South Africans and African migrants in the host society occur under different conditions. In this respect, the type of migration African people are subjected to influences their marriages and sexual relations. According to the past and current studies, there are different types of migration and migrants. In the context of this study, an African migrant is a person from another African country who moved into South Africa for one reason or another. This person might be a refugee, jobseeker, asylum seeker or another foreign person. Because migration occurs under different conditions and marriage under different circumstances, challenges and opportunities for their marriage in South Africa can be, to a significant extent, predicted by ulterior motives of their migration into South Africa. Below follows the research methodology.

\section{Research Methodology}

This study is based on data collected through interviews with South Africans and African migrants in the City of Cape Town, Western Cape of South Africa. With relation to the data size, twenty people have been interviewed among them ten African migrants (seven men and three women, all Black from different nationalities) and ten South Africans (six women and four men of all races: White, Black, Coloured, and Indian). I have used a qualitative approach and therefore a purpose sampling. This sampling is at the same time selective and subjective. The participants of this study, all adults from different age categories, have been selected in different areas of the City of Cape Town Metropolitan Municipality, and more precisely in public spaces (metropolitan beaches, municipal libraries and communal gardens).

For the data collection, I have used a Blaupunkt Internet Tablet ETAB M7023G for recording the interviews that I have transcribed. For the data analysis, I have classified and categorised the data under two main themes by taking into consideration on one side their relevance to challenges and on the other their significance to opportunities of intermarriages. Therefore, the unit 
of analysis consists of interviews based on perceptions and experiences of South Africans and African migrants living in the City of Cape Town, the terminology of marriage has been defined and its meanings highlighted. This data was analysed in order to reveal the challenges and opportunities of intermarriages in the City of Cape Town.

Some significant methodological issues are to be disclosed in this study. My situation and condition as a Black African migrant have somehow positively and/ or negatively affected the responses of some people I have interviewed. Many African migrants, men in particular, expressed themselves more freely and some South Africans, men especially expressed themselves less freely. This can be enlightened and influenced by the experiences of their social interactions with the female counterparts on one hand or the male counterparts on the other.

\section{Theoretical Framework}

Contact theory has been used for many years by studies focusing on intergroup relations. A vast amount of similar research uses intergroup contact theory among others, Mohaupt et al. (2012), Carpenter and Dickinson (2016), Efe Mary Isike (2017). Intergroup theory is fundamental to explain social realities and practices in inter-personal, inter-professional, inter-cultural, multicultural and diverse settings, where people from different backgrounds interact. Contact between people suggests forms of integration or inclusion on the one side, and on the other, forms of discrimination or exclusion. In this regard, social situations, psychological conditions and socio-cultural foundations play a very big role. In the context of this study, intergroup contact theory is important in assessing, analysing and explaining the challenges and opportunities of mixed marriages and sexual relations between African migrants and South Africans.

The theoretical aspect of this study is framed on intergroup contact theory developed by Gordon William Allport (1954) and expanded by Thomas Pettigrew and Linda Tropp (2011). In relation to contact theory, Gordon William Allport (1954) recognized and specified four particular conditions for optimal intergroup contact: equal group status within the setting, common goals for both groups, cooperation between the in-group and the out-group, and operational authority support for both groups. Regarding social relations, prejudice and hostility between in-groups and out-groups can be predicted. In 
this regard, Thomas Pettigrew and Linda Tropp (2011: 2) argue that 'intergroup contact can be a significant remedy for combating prejudice and hostility between groups. Many commentators have held optimistic views regarding the potential for intergroup contact to improve intergroup relations. A popular refrain among advocates of integration is 'if only we could get people from different groups to come together', then we would be able to achieve improved relations between groups. Unfortunately, achieving positive effects of intergroup contact is not always so simple'.

On the one hand, intergroup relations can be improved when members of different groups come together and become connected. This connection erases previously existing prejudice and hostility. On the other hand, it may also appear under certain circumstances that whenever members of different groups come together, prejudice and hostility still exist. In this case, there is no connection or association.

The lack of connection or hospitality can, but not necessarily, lead to racism and/ or xenophobia in the context of this study. In relation to this research, the potential question is to understand to what extent marriages and sexual relations between African migrants and South Africans, in general, can be improved when these two categories (African migrants and South Africans) come together. In this regard, it seems to be predictably optimistic and pessimistic views.

With reference to optimistic views, more contact between African migrants and South Africans of all races will improve marriage relations and sexual relations between the two groups. In this context, contact reduces prejudice and hostility. Pessimistic views suggest that despite the frequency of contact between African migrants and South Africans, prejudice and hostility still exist when it comes to marriage and sexual relations between the two groups. In this context, contact does not improve intergroup relations. There is a possibility of third views that I call 'blended views'. Under certain circumstances, blended views in the context of this study can be seen as a combination of pessimistic views and optimistic views. The analysis and the findings of the study follow below.

\section{Analysis and Findings}

There are challenges and opportunities expressed through different views about marriage and sexual relations between African migrants and South 
Africans of all races in present-day post-apartheid South Africa. The migration of Africans from other African countries into South Africa and their contact with local South Africans in general plays a significant role in intergroup relations by improving marriage and sexual relations. It is significant to underline in this study the conflict between traditionalistic or conservative behaviours and modernistic ways of life in the City of Cape Town.

There is in a marriage or a sexual relationship more than the physical presence of the two persons involved. Marriage and sexual relations also suggest the intellectual, spiritual, and emotional characteristics of the persons in interactions. Marriage is at the same time an internal and external window of human relations through which interests and cultural backgrounds play a fundamental role.

In the context of the findings of this study, some challenges open doors for opportunities to a certain extent. At a certain level, some aspects of marriage and sexual relations are seen as opportunities by some participants and viewed as challenges by others. For that reason, there is no clear-cut between challenges and opportunities of marriage and or sexual relations between African migrants and South Africans in general.

\section{Opportunities for Marriage and Sexual Relations between African Migrants and South Africans}

With reference to most of the interviews I have conducted in this regard, there are optimistic views revealing opportunities for marriage and sexual relations between African migrants and South Africans in general. As a male African migrant says 'I will get married to a South African woman for love so that we can build our common life and future together. With a black South African woman, it is easier for me. We are from the same race and we are all Bantu. In fact, our cultures are more similar than different' ( $\mathrm{Mr} \mathrm{B}$, personal communication, 17 September 2017).

Another African migrant says: 'If I have the opportunity to marry a South African woman, I will do so. I will never marry a woman from the home country I meet in South Africa because they travel or migrate to South Africa by their own and they have their own hidden agenda. It will be very risky for me to marry a woman from my home country I meet in South Africa' (Mr D, personal communication, 20 September 2017). This means that male African migrants feel more integrated and welcomed by Black South African women. 
This can also be explained, under certain conditions, by the fact that Black South African women are more relationally and sexually liberal and liberated. This may be the opposite in the case where female African migrants living in South Africa are relationally and sexually traditional and more sexually committed and submissive mostly to men from their own nationality or cultural background.

As suggested by the findings, it is easier for an African migrant to get married to a Black South African woman than to get married to a Coloured or White South African woman. This is also the case with sexual relations. Marriage and sexual relations in this context are more racial or race-related and sometimes racialist.

Findings of this study suggest that race plays a crucial role in marriage and sexual intercourse between African migrants and South Africans in general. One of the participants to this study, a White South African woman who considers herself as Caucasian and not White expressed herself in this way: 'I am not White, I am Caucasian. There are a lot of obstacles in any relation. Everybody has his or her own culture: culture within the family, the community and the society. My father is a quite racist person. I have a respect for him and for this reason; I will never marry or have sexual relations with a man outside my racial background. I think a man from my racial background will understand me better as we have the same culture' (Ms G, personal communication, 23 September 2017).

The legacy of apartheid, under certain circumstances, still exists in present-day post-apartheid South Africa and it manifests itself through racism in relation to intergroup relations. By means of projecting the future, there will not be a rapid change or transformation in interracial marriages and interracial sexual relations concerning African migrants and South Africans in South Africa and more specifically in the City of Cape Town. After twenty-two years of freedom and democracy, marriage and sexual relations in South Africa are still predominantly xenophobic or intolerant and racially prejudiced.

Some African migrants, as well as some South Africans, do have racial or race-related preferences concerning marriage and sexual relations. A male African migrant argues, 'If I bring a White woman to my home country, my family will reject her and me. My family will reject both of us. In my home country, my family does not know about White woman. My family members think that Whites and Blacks do not have the same traditions and cultures' (Mr P, personal communication, 17 September 2017). Race, as a social construc- 
tion, becomes a very big issue in this context. Human beings of all nationalities and races are somehow consciously or subconsciously discriminatory and to some extent racist. Race and racism, to a significant extent, are very big social topics of discourse and or conversation when it comes to marriage and sexual relations globally, more locally in South Africa, and more precisely in the City of Cape Town.

\section{Challenges of Marriage and Sexual Relations between African Migrants and South Africans}

There are diverse pessimistic views revealing challenges and sexual relations between African migrants and South Africans in general. In this regard, a female African migrant says: 'South African men are too discriminatory and racist. The majority of them do not like marrying or having sexual relations with African migrant women. If they have an opportunity, they just want to explore sexual relations with African migrant women and they disappear. I do not consider marriage or sexual relations with South African men because of cultural differences. South African men seem to be not committed to intergroup relations' (Ms M, personal communication, 20 September 2017).

It is very rare, but not excluded, in the City of Cape Town, to find a female African migrant interracially engaging openly in marriage or marriage relationships with male South Africans. In most interracial relationships involving female African migrants and White men in the City of Cape Town, the White male counterparts or partners are not from South Africa, but they come from Europe. White South African men are too selective and discriminating in this concern. This can also be influenced by the fact that South African women, as many South African men and non-South African men I have interviewed indicated, are more beautiful and more attractive than African migrant women. Beauty and sexuality to a certain extent constitute emotional and sometimes useable principles of choice in this concern.

A White male South African says: 'I will never marry an African migrant woman. We have different cultural backgrounds and identities. My parents will not allow it to happen' (Mr W, personal communication, 23 September 2017). The challenges here are cultural differences, cultural resistance and difficulties of acceptance. This view is justified by the fact that 'Most men who live to maturity belong to two elementary families, to one as son and brother, and to the other as husband and father. It is this simple fact 
that gives rise to a network of relations connecting any single person with many others' (Radcliffe-Brown \& Daryll 1950: 6). Language as a tool of communication is sometimes viewed as a challenge for intermarriage. It is important to note that, not all African migrants living in South Africa would like to settle because they migrated for many different reasons.

A male African migrant says: 'There are difficulties for me to get married to a South African woman because one day, I will go back to my home country. On top of this, there is a conflict of cultures and South African women do not support their husbands in bad times. I will only get married to a South African woman if I am looking for a residence permit to stay in South Africa' (Mr A, personal communication, 17 September 2017). Another male African migrant says, 'I will never choose to get married to a South African woman, but I can have sexual relations with a South African woman' (Mr C, personal communication, 20 September 2017).

It is central to emphasize in this regard that, marriage as commitment and sexual relations as freedom carry different meanings under different circumstances in the context of contact between African migrants and South Africans in general. Under many circumstances, marriage traditionally involves sexual relations, but sexual relations do not necessarily imply marriage. For some male African migrants, marriage and sexual relations with female South Africans are based on profit and interest. In this case, the age and the race of the female South African partners or spouses do not really matter for these African migrants. Their female South African counterparts may possibly be older than them. Age and race sometimes matter when it comes to true romantic love where educational and or professional connections play a big role.

'I cannot marry a South African woman. A South African woman will not allow me to go back to my home country to stay there with her and the children. Marriage and sexual relations between African migrants and South African women are just for a period of time' (Mr J, personal communication, 17 September 2017). This view can be revealed by related experiences of many other African migrants in South Africa who have married South African women and marriage did not last for one reason or another.

Some African migrants are willing to marry South African women, but at a certain point, these African migrants think twice and do not see a lifelong commitment of South African women in these marriage relations. In this case, intermarriage becomes a very big challenge for African migrants. Many 
African migrants think that the better risk for them is to marry a woman from their own country. Indisputably, they do not see or have any problem by having sexual relations with South African women. For many African migrants and for some South African women, sexual relations do not imply commitment. But marriage, in its traditional sense, is supposed to be a lifelong attachment. Sexual relations can be hidden or discreet, but marriage, to a significant extent, cannot be discreet.

A South African woman says: 'I would not aspire to marry an African migrant. I would like to marry a person from my own Coloured cultural background because men from other cultures are using us. I will be friend of African migrants, but I will not aspire having sexual relations with them. Some men pretend they love you, but they disrespect you. A woman needs a person who respects her and probably falling in love with the person' (Ms K, personal communication, 23 September 2017). This may be revealing that getting married interracially is for a particular interest and profit. And because of the powerful forces at work, one partner might be using or abusing another one in one way or another.

Some African migrants consider marriage and sexual relations in the South African context commonly as racist or racialist. A male African migrant says: 'With Coloured and White women, there is what we can call racism' (Mr E, personal communication, 20 September 2017). Sometimes, sexual relationships between African migrants and non-Black South African women are discreet because many South African parents do not want their adult children to be in sexual relations or marriage with African migrants. This pressure of South African parents on their adult children is a great problem in South African society in general and in the City of Cape Town in particular. Many African migrants do not feel the pressure of their parents or family members because they have left them, sometimes a long time ago in their country of origin.

\section{Blended Views}

A male African migrant says: 'As African migrant, I am not contemplating to marry a South African woman and leave her behind. But if circumstances allow me to stay in South Africa forever, I can marry a South African woman. When I was a newcomer, I met a White South African lady whose mother was from here (South Africa) and whose father was from Portugal. She wanted to marry 
me, but I refused because I was still new in the country. I was beginning looking for better life. I was not financially prepared at that moment. According to my culture the man is the provider. Since then, she did not come to me anymore and I did not see her anymore. I do not know her whereabouts. I am a Muslim, but Islam allows Muslims to marry Christian women and the children can choose their own religion. It is better to discuss before getting married to see if you accept each other' (Mr N, personal communication, 17 September 2017). In this concern, marriage is based on mutual acceptance and agreement of both partners. This suggests that cultural tolerance is the primordial and cultural difference is complementary for people involved in this kind of social relations and social institutions. In relation to this view, 'marriage is a social arrangement by which a child is given a legitimate position in the society, determined by parenthood in the social sense' (Radcliffe-Brown \& Daryll 1950: 5).

A male African migrant says: 'I did not marry my current (South African) wife for citizenship or for identification document to stay in South Africa. I did have the document that allows me to stay in the country long time before we got married. I did marry a South African woman because I was deceived by a woman from my own country that I left behind as fiancée before I migrated into South Africa. When I was not there (in my country of origin), she got pregnant from another man. I want to be with a woman I want to see every day next to me' (Mr L, personal communication, 20 September 2017). As previously revealed, many African migrants consider marriage with women from their own country of origin. But there are sometimes dissatisfactions. These disappointments might open doors for them to marrying South African women. African migrants who have been deceived by women of their own country of origin and African migrants who have migrated for many years and do not have any connection in this regard back in their country of birth, find it easier and better to marry South African women. The conclusion of the study follows below.

\section{Conclusion}

The focus of this chapter is on the challenges and opportunities of marriage and sexual relations between African migrants and South Africans, in general, living in the City of Cape Town. This study reveals that marriages and sexual relations between South Africans and African migrants living in the City of 
Cape Town are characterized sometimes by hostility and selectiveness that imply xenophobia, intolerance and racism. In most responses, xenophobia and racism hinder mixed marriages between African migrants and South Africans. However, integration and assimilation help intermarriages in Cape Town, Western Cape of South Africa. But it is more common in the South African context to assimilate African migrants, who are from time to time seen under certain circumstances as foreigners, strangers and outsiders, into the family, the community, the society, if these African migrants are willing to be incorporated through 'inclusionary marriage' profoundly based on romantic love and not dependently built on profit and interest as is the case of 'exclusionary marriage'.

This study suggests that many African migrants and many South Africans living in the City of Cape Town strongly believe that only people of their own and respective backgrounds can profoundly understand and really appreciate marriage and sexual relations. However, some African migrants and some South Africans believe that marriage and sexual relations in general have no cultural, racial, national or religious boundaries. Therefore, this view is explained by the phenomenon of globalization in present-day post-apartheid South Africa. With the fall of legal apartheid and the softening of conservative cultures, the City of Cape Town and its people are increasingly exposed to the world and the world is totally exposed to them. African migrants and South Africans must use the opportunities offered to them by the phenomena of migration and globalization to accommodate their individual and personal needs in relation to marriage and sexual relations inside and outside their country of origin.

\section{References}

Aldridge, D.P. 1978. Interracial Marriages: Empirical and Theoretical Considerations. Journal of Black Studies 8, 3: 355 - 368. Available at: https://www.jstor.org/stable/2783649 (Accessed on 25 November 2016.) https://doi.org/10.1177/002193477800800308

Allport, G.W. 1954. The Nature of Prejudice: The Classic Study of the Roots of Discrimination. Boston: Addison-Wesley Publishing Company. Anderson, K.J. 2010. Benign Bigotry: The Psychology of Subtle Prejudice. New York: Cambridge University Press. https://doi.org/10.1017/CBO9780511802560 
Azzolini. D. \& R. Guetto 2015. Guetto, R. 2015. The Impact of Citizenship on Intermarriages. Quasi-experimental Evidence from two European Union Eastern Enlargements. Working Papers, Research Institute for the Evaluation of Public Policies (IRVAPP), Bruno Kessler Foundation. Available at: https://epc2016.princeton.edu/papers/160590

(Accessed on 25 November 2016.)

Bohra-Mishra, P. \& D.S. Massey 2015. Intermarriage among New Immigrants in the USA. Ethnic and Racial Studies 38, 5: 734 - 758. Available at:

http://dx.doi.org/10.1080/01419870.2014.937726

(Accessed on 27 November 2016.)

https://doi.org/10.1080/01419870.2014.937726

Carpenter, J.S.W. \& C. Dickinson 2016. Understanding Interprofessional Education as an Intergroup Encounter: The Use of Contact Theory in Programme Planning. Journal of Interprofessional Care 30, 1: 103. Available at: https://doi.org/10.3109/13561820.2015.1070134

(Accessed on 28 November 2016.)

https://doi.org/10.3109/13561820.2015.1070134

Chi, M. 2015. Does Intermarriage Promote Economic Assimilation among Immigrants in the United States? International Journal of Manpower 36, 7: 1034 - 1057. Available at: https://doi.org/10.1108/IJM-05-2013-0112 (Accessed on 25 November 2016.)

https://doi.org/10.1108/IJM-05-2013-0112

Cukras-Stelągowska, J. 2016. Mixed Marriages in the Jewish Community: Aberration or Social Norm? Family Upbringing 14,2: 317 - 339. Available at:

http://pedagogika.uni.wroc.pl/Instytut-

Pedagogiki/Aktualnosci/Ogloszenia

(Accessed on 20 January 2017.)

Elwert, A. 2016. Opposites Attract - Evidence of Status Exchange in Ethnic Intermarriages in Sweden Lund Papers in Economic History. Population Economics 147. Available at:

https://portal.research.lu.se/portal/files/10711408/LUP 147 June.pdf (Accessed on 19 January 2017.)

Fredrickson, G.M. 2002. Racism: A Short History. Princeton: Princeton University Press. Available at: https://trove.nla.gov.au/version/25291672 (Accessed on 25 November 2016.)

https://doi.org/10.1515/9781400873678 
Gray, A. 1987. Intermarriage: Opportunity and Preference. Population Studies 41, 3: 365 - 379. Available at:

https://doi.org/10.1080/0032472031000142956

(Accessed on 27 November 2016.)

Isike, E.M. 2017. A Contact Theory Analysis of South Africans' Perceptions of Nigerian Immigration. Etude de la Population Africaine 31,1: 3225 3233. Available at: https://doi.org/10.11564/31-1-955

(Accessed on 18 February 2018.) https://doi.org/10.11564/31-1-955

Kalmijn, M. 2010. Consequences of Racial Intermarriage for Children's Social Integration. Sociological Perspectives 53,2: 271 - 286. Available at:

https://doi.org/10.1525/sop.2010.53.2.271

(Accessed on 26 November 2016.)

Kuzituka, D.J.M. 2009. National Identity and Immigration from Africa: Relationships between Black South Africans and African Immigrants in Yeoville. Johannesburg: Wits University Press. Available at:

http://hdl.handle.net/10539/7068

(Accessed on 27 November 2016.)

Mayer, E. 1985. Love and Tradition: Marriage between Jews and Christians.

Modern Judaism, 6, 2: 211 - 213. Available at:

https://www.jstor.org/stable/1396102 211-213

(Accessed on 23 February 2017.)

Mojapelo-Batka, E.M. 2008. Interracial Couples within the South African Context: Experiences, Perceptions and Challenges. Pretoria: University of South Africa. Available at:

http://uir.unisa.ac.za/bitstream/handle/10500/2153/thesis.pdf?sequence= 1 \&isAllowed $=\mathrm{y}$

(Accessed on 25 November 2016.)

Mohaupt, J., M. van Soeren, M.-A. Andrusyszyn, S. Devlin-Cop \& S. Reeves 2012. Understanding Interprofessional Relationships by the Use of Contact Theory. Journal of Interprofessional Care 26, 5: 370 - 375. Available at: https://doi.org/10.3109/13561820.2012.673512 (Accessed on 25 November 2016.)

Mutwa, C.V. 1986. Let not My Country Die. Pretoria: United Publishers.

Mwakikagile, G. 2008. African Immigrants in South Africa. Cape Town: New Africa Press.

Parsonson, K. 1987. Intermarriages: Effects of the Ethnic Identities of the Off- 
spring. Journal of Cross-Cultural Psychology 18, 3: 363 - 371. Available at: http://dx.doi.org/10.1177/0022002187018003006

(Accessed on 23 February 2017.)

https://doi.org/10.1177/0022002187018003006

Pettigrew, T.F. \& L.R. Tropp 2011. When Groups Meet: The Dynamics of Intergroup Contact. New York: Psychology Press.

Pue, G.H. \& N. Sulaiman 2013. Choose One! Challenges of Inter-ethnic Marriages in Malaysia. Asian Social Science 9, 17: 269 - 278.

http://dx.doi.org/10.5539/ass.v9n17p269

(Accessed on 25 November 2016.)

https://doi.org/10.5539/ass.v9n17p269

Radcliffe-Brown, A.R. \& F. Daryll (eds.) 1950. African Systems of Kinship and Marriage. London: Oxford University Press.

Roer - Strier, D. \& D. Ben Ezra 2006. Intermarriages between Western Women and Palestinian Men: Multidirectional Adaptation Processes. Journal of Marriage and Family, 68, 1: 41 - 55. Available at:

http://dx.doi.org/10.1111/j.1741-3737.2006.00232.x

(Accessed on 29 November 2016.)

https://doi.org/10.1111/j.1741-3737.2006.00232.x

Satake, M. 2004. Filipina-Japanese Intermarriages: A Pathway to New Gender and Cross-Cultural Relations. Asian and Pacific Migration Journal, 13, 4: 445-47. Available at:

https://doi.org/10.1177/011719680401300403

(Accessed on 25 November 2016.)

https://doi.org/10.1177/011719680401300403

Schwartz, C.R. \& Z.Z. Yu Xie 2016. Marrying Up by Marrying Down: Status Exchange between Social Origin and Education in the United States. Sociological Science 3: 1003 - 1027.

https://doi.org/10.15195/v3.a44

(Accessed on 19 February 2017.)

Solomons, J. \& L. Back 2002. Race, Politics and Social Change. London: Routledge.

South African History Online. Available at:

https://www.sahistory.org.za/dated-event/prohibition-mixed-marriagesact-commences

(Accessed on 25 November 2016.)

Waters, M.C. 2000. Immigration, Intermarriage, and the Challenges of Mea- 
Marius D. Mbetga

suring Racial/ Ethnic Identities. American Journal of Public Health 90, 11: 1735 - 1737. Available at:

https://www.ncbi.nlm.nih.gov/pmc/articles/PMC1446407/pdf/11076242. pdf

(Accessed on 18 February 2017.)

https://doi.org/10.2105/AJPH.90.11.1735

Zebroski, S.A. 1999. Black-White Intermarriages: The Racial and Gender Dynamics of Support and Opposition. Journal of Black Studies 30, 1: 123 - 132. Available at:

https://www.jstor.org/stable/2645896

(Accessed on 25 November 2016.)

https://doi.org/10.1177/002193479903000107

Marius D. Mbetga

Doctoral Candidate

Sociology

University of the Western Cape madibalanza@gmail.com 